\title{
As narrativas das crianças sobre as práticas educativas do Mouimento de Mulheres Camponesas'
}

\author{
Narratives of children about the educational practices in the Farming \\ womem Movement
}

\section{Las narrativas de lo niños acerca de las prácticas educativas del Movimiento de las Mujeres Campesinas}

\author{
Zenaide Collet $^{2}$ \\ Rede Pública Estadual em Quilombo, SC, Professora \\ Maurício Roberto da Silua ${ }^{3}$ \\ Universidade Federal de Santa Catarina, Professor aposentado
}

Resumo: Com o presente artigo tem-se o intuito de divulgar, por meio das narrativas capturadas de depoimentos orais, a voz da criança camponesa, colocando em destaque suas representações em diálogo com as mãesmilitantes. A pergunta-problema que orientou a pesquisa foi: no âmbito do diálogo entre crianças e mulheres-mãe militantes, quais as representações sociais sobre o processo formativo e as práticas educativas construídas nas lutas do Movimento de Mulheres Camponesas? Na perspectiva epistemológica, tomamos como referência algumas reflexões sobre as leis e categorias da dialética materialista da história em articulação com alguns aportes do pensamento freireano. Inspiramo-nos na abordagem teórico-metodológica do Círculo Epistemológico de Cultura (CEC), realizado concomitantemente com os encontros de mulheres. Em termos de conclusões provisórias, foi possível perceber nas narrativas que as crianças conhecem os meandros político-

texto é composto por uma fração das discussões tecidas em uma dissertação apresentada ao Programa de Pós-Graduação Stricto Sensu em Educação da Universidade Comunitária da Região de Chapecó (Unochapecó) como requisito ao título de mestre.

2 Mestre em Educação pelo Programa de Pós-graduação em Educação Stricto Sensu da Universidade Comunitária da Região de Chapecó (Unochapecó); Especialista em Ciências Sociais: Geografia e História pelo Instituto de Desenvolvimento Educacional do Alto Uruguai (IDEAU); Militante do Movimento de Mulheres Camponesas (MMC); Bolsista da UNIEDU/FUMDES.

3 Pós-Doutor pela Universidade do Minho, Portugal; Doutor em Ciências Sociais Aplicadas à Educação (DECISARE/Unicamp). 
pedagógicos das práticas educativas e desejam participar de um projeto popular igualitário em um ambiente político-social de militância.

Palavras-chave: Movimento de Mulheres Camponesas. Crianças camponesas. Práticas educativas.

Abstract: This paper aims to provide a voice through the narratives with oral testimonies of the peasant children by highlighting one's representations in dialogues with the militant mothers. The problem question that guided the research was: in the dialogue context between children, women and militant mothers, what social representations about the formative process and educational practices were built during the fights for the movement? By the epistemological perspective some references were taken into consideration such as the laws and materialist dialectic categories of history in conjunction with some contributions about the Freirean thoughts. The research was inspired by the theoretical methodological approach of the Epistemological Circle of Culture (CEC) which was carried out simultaneously with women meetings. In terms of provisional findings it was possible to observe through the narratives that the people involved know the political pedagogical meanders of educational practices and also wish to participate in an egalitarian popular project into a politico social militancy.

Keywords: Movement of Farming Women. Peasant children. Educational practices.

Resumen: El presente artículo tiene como objeto divulgar a través de los relatos con declaraciones orales de los niños campesinos pondo atención en sus representaciones en diálogo con las madres-militantes. La preguntaproblema que orientó la pesquisa fue: ¿En el ámbito de lo diálogo entre niños y mujeres-madres militantes, cuáles las representaciones sociales sobre el proceso formativo y prácticas construidas en las luchas del movimiento? En la perspectiva epistemológica, adoptamos como referencia algunas reflexiones sobre las leyes y categorías de la dialéctica materialista de la historia en articulación con algunos insumos del pensamiento "freireano". Nos inspiramos en el enfoque teórico-metodológico del Círculo Epistemológico de la Cultura (CEC), realizamos simultáneamente con los encuentros de la mujeres. Lo que se refiere a las conclusiones provisionales, fue posible percibir en las 
narrativas que ellos conocen los meandros políticos-pedagógicos de las prácticas educativas y desean participar de un proyecto popular igualitario en un ambiente político-social de militancia.

Palabras clave: Movimiento de las Mujeres Campesinas. Niños campesinos. Prácticas educativas.

\section{INTRODUÇÃO}

No artigo tem-se como escopo refletir e analisar as narrativas das crianças do Movimento de Mulheres Camponesas (MMC) sobre as práticas educativas realizadas no interior desse Movimento Social. Vale destacar que, em geral, as narrativas podem ser consideradas um importante recurso metodológico em pesquisas qualitativas, podendo ser realizadas a partir de relatos ou depoimentos orais e escritos e informações verbais. Nesta pesquisa, optamos pela entrevista narrativa, cujo eixo metodológico é uma variante do depoimento oral e pode possibilitar a fusão das trajetórias de vida dos sujeitos (crianças e mulheres do MMC) em contextos sócio-históricos e políticos. É possível compreender a narratividade em sua dimensão de depoimento oral como uma forma artesanal de comunicação, cujo objetivo é veicular conteúdos, ideias e representações a partir dos quais as experiências objetivas e subjetivas, presentes no imaginário de crianças e adultos, podem ser transmitidas, respeitadas e problematizadas no contexto de construção do objeto de estudo. Em síntese, ela busca obter informações e testemunhos dos sujeitos entrevistados sobre as suas vivências em determinadas situações ou sobre suas participações em determinadas instituições que se pretende investigar (LANG; CAMPOS; DEMARTINI, 2010, p. 45; MUYLAERT, 2014, p. 193).

A pergunta-problema que orientou a pesquisa e revelou as narrativas das crianças do MMC foi: quais as representações sociais, no âmbito do diálogo com as mulheres-mães militantes, sobre o processo formativo e práticas educativas construídas nas lutas do movimento? Da perguntaproblema emergiram outras questões de pesquisa, a saber: o que é ser criança 
camponesa e qual seu lugar (papel) no Movimento à luz das representações das próprias crianças e das mulheres-mães militantes do MMC? Como as crianças camponesas estão inseridas no processo de organização, formação e lutas do MMC?

$\mathrm{Na}$ perspectiva epistemológica e teórico-metodológica, tomamos como referência algumas reflexões sobre as leis e categorias da dialética materialista da história em articulação com alguns aportes do pensamento freireano. Do ponto de vista do gênero, considerando as especificidades das lutas das mulheres camponesas no limiar do "feminismo camponês", baseamo-nos em alguns elementos teórico-conceituais de Saffioti (2013, 2015), principalmente no que diz respeito à "diretriz do nó" (SAFFIOTI, 1999, p. 9) e suas possíveis articulações entre classe social, gênero (Movimento de Mulheres Camponesas) e geração (infância).

Ademais, para pensar um diálogo entre as mulheres do $\mathrm{MMC}$ e as crianças, foi imprescindível trazer à tona as reflexões sobre o patriarcado, uma vez que essa questão permeia os aportes teórico-metodológicos do já evocado feminismo camponês. Em seu livro Gênero, patriarcado e violência, Saffioti (2015, p. 129) esclarece "[...] que o patriarcado se baseia no controle e no medo, atitude e sentimento que formam um círculo vicioso" de dominação e exploração. Essa relação não se limita às relações de gênero; pelo contrário, perpassa as instituições e toda convivência social, tendo em vista que algumas "[...] pessoas podem se situar fora do esquema de dominação/exploração das classes sociais ou do de raça/etnia. Ninguém [...] fica fora do esquema gênero patriarcal." (SAFFIOTI, 2015, p. 130). E as relações patriarcais se revelam a todo momento na vida cotidiana das mulheres desde a infância.

No que tange às reflexões sobre a infância, tomamos como referência os estudos que articulam infância e classe social (SILVA, 2003; ARENHART, 2007), para, assim, poder pensar nas possíveis especificidades da infância camponesa. Para Silva (2003, p. 52), nos estudos sobre a infância empobrecida, é preciso entender a infância como uma construção social, política, econômica e histórica, sem perder de vista as demais categorias sociológicas, como gênero, raça/etnia e geração, as quais devem fazer parte 
do esforço de articulação previsto na noção/diretriz do nó de Saffioti (1999) já evocada anteriormente. Portanto, a fim de elaborar a noção de criança camponesa, tornou-se necessário, primeiramente, recorrer aos estudos de Arenhart (2007), que investigou as crianças em luta pela terra do Movimento dos Trabalhadores Rurais Sem Terra (MST). A autora reafirmou a concepção de infância camponesa, que deve ser compreendida "pela 'presença' de outras características, diferentes dos adultos." (ARENHART, 2007, p. 39).

Outra questão seminal quando está em jogo o diálogo das crianças com os adultos (mulheres do MMC) é a relação entre a concepção de infância e a importância das representações e vozes das crianças, a fim de se pensar nas suas contribuições para o movimento. Valorizar "[...] as representações sociais nas interações, nas contradições de classe e nas expressões de qualquer grupo social [...]" (MINAYO, 2014, p. 232), assim como em cada momento histórico, significa dizer que é de suma relevância pensar a infância, não somente por seus próprios méritos ou pela ideia de "criança em si", mas pensar as crianças na totalidade social em que vão se constituindo como sujeitos históricos e cidadãos, a partir de seus diálogos e relações com as mulheres do movimento (BARATA; MOURA apud LAMARE, 2016, p. 148-149).

Em relação aos procedimentos teórico-metodológicos de abordagem da realidade, tomamos como fonte de inspiração os estudos de Romão et al. (2006, p. 173) sobre o Círculo Epistemológico de Cultura (CEC). Os autores reinterpretaram os Círculos de Cultura de Paulo Freire, apresentando-os não apenas como uma possibilidade "de instrumento de pesquisa ou investigação científica, mas principalmente [...] como uma possibilidade teóricometodológica, de ação-reflexão, que toma como base alguns dos pressupostos ontológicos e epistemológicos." Nesses termos:

$\bigcirc$ círculo epistemológico de cultura permite que o pesquisador e o pesquisando reflitam sobre o objeto investigado, mobilizados por uma questão geradora de debate. A partir dela, acontece a enunciação de situações existenciais, carregada de conteúdo emocional, manifesto pelo universo cultural vocabular. Ambos, pesquisador e pesquisando, analisam os temas e subtemas codificados e decodificados, a partir dessas situações existenciais, 
mediados pela problematização das situações. Ao proceder dessa forma, eles denunciam suas condições existenciais, movidos pela ação-reflexão-ação e pela proposição de saídas para o impasse, anunciando novas possibilidades de intervenção na realidade. (ROMÃO et al., 2006, p. 185).

O CEC foi construído da seguinte forma: em um primeiro momento, as mulheres-mães militantes e as crianças participaram de místicas, jogos e brincadeiras do Teatro do Oprimido, de Boal (2007), publicado em seu livro Jogos para atores e não atores, além das dinâmicas de apresentação do grupo de diálogo sobre o objetivo e metodologia do CEC para o desenvolvimento da pesquisa.

Em um segundo momento, o objetivo do CEC com as crianças em que foi retomado o encontro em forma de diálogo lúdico. Assim, foi realizada uma apresentação e discussão sobre os seguintes aspectos: a importância das fotografias e do vídeo para a pesquisa e a proposta das atividades. Em seguida, iniciou-se a dinâmica com o jogo brincando com o nome. No terceiro momento, iniciou-se o CEC propriamente dito, com dinâmica de perguntas sobre o ser criança camponesa e sua relação com as práticas educativas no MMC, no que se refere a questões da produção da vida, como trabalho, educação, família, direitos, lutas, quintais produtivos, plantas medicinais, sementes crioulas, entre outras.

No quarto momento, organizamos juntos as brincadeiras escolhidas pelo grupo, como pular corda, alerta, caçador e brincadeiras de roda. Logo após, tempo livre para o almoço. Na sequência, reiniciamos as atividades com as crianças, motivando-as a "brincar de entrevistas" no diálogo com as mulheres-mães. Em seguida, refletimos sobre o que havia sido debatido pela manhã, iniciando esse momento com a dinâmica do jogo do espelho. Daí em diante começou efetivamente o diálogo entre as crianças e as mulheres sobre diversas questões: origem do MMC e suas lutas, participação das crianças nos processos formativos do Movimento, experiências marcantes para a vida das mulheres e, por fim, as diversas dimensões das práticas educativas.

No quinto momento, foram realizados jogos teatrais, nos quais crianças e mães interagiram em brincadeiras como adivinha e coelhinho sai da toca. 
Também lançamos mão do Diário de Campo (DC) como instrumento de registro de informações significativas, não apenas no momento do CEC. $\bigcirc$ próprio Freire (2014 p. 142) orientava os educadores a identificar o "tema gerador", assim como procurar conhecer as relações interpessoais do grupo envolvido. Fizemos uso do DC para registrar informações significativas da relação entre mulheres e crianças, levando em conta a necessidade de mergulhar na realidade e fazer com que os sujeitos participassem efetivamente dos processos educativos, ou seja, segundo Freire (2014), “[...] quanto mais investigo o pensar do povo com ele, tanto mais nos educamos juntos." Por isso, no decorrer do texto, recorremos ao DC, fazendo referência não apenas às crianças que participaram do $\mathrm{CEC}$ e, consequentemente, às práticas educativas com suas mães durante o período da pesquisa, mas também a outras crianças que integram o MMC.

Freire (2014), quando se refere ao tema gerador, busca chamar atenção para a importância de se envolver na vida dos sujeitos, visando melhor compreendê-los. $\bigcirc$ autor sugere aos pesquisadores participação na vida comunitária, como, por exemplo, nas reuniões e noutros momentos, seja na família, no lazer, seja no trabalho, observando o envolvimento do grupo, a linguagem usada, as manifestações em relação às mulheres, mulheres-mães e homens-pais, mulheres e crianças, mães e filhos e outros. Tudo isso para estabelecer uma relação mais coerente entre os sujeitos e o objeto da pesquisa e, consequentemente, a práxis enquanto "[...] reflexão e ação dos homens sobre o mundo para transformá-lo." (FREIRE, 2014, p. 52).

Do ponto de vista das análises dos dados, enfrentamos o desafio de ouvir e respeitar as narrativas das crianças, mas, ao mesmo tempo, tentamos fazer algumas reflexões sobre as representações relacionadas às práticas educativas contidas em suas narrativas. Nessa perspectiva, tomamos como inspiração a análise hermenêutico-dialética (MINAYO, 2014), que busca a articulação entre as potencialidades da hermenêutica e as leis e categorias do materialismo histórico-dialético. Todavia, essa não foi uma tarefa fácil, considerando-se os limites e possibilidades da construção do objeto. Ademais, tomamos como referência para a análise dos dados, as unidades de registro e contexto, as quais foram construídas à luz dos temas geradores (categorias empírico-teóricas). 
Com base nesses procedimentos analíticos, realizamos a "análise de conteúdo temático", a partir da noção de "temas geradores freireanos", ou seja, uma afirmação a respeito de determinados assuntos e conteúdos que se destacam no âmbito da construção teórico-empírica do objeto (MINAYO, 2014).

Postas essas questões teórico-metodológicas, apresentamos, daqui em diante, algumas evidências empíricas oriundas do DC, além das reflexões teóricas que subjazem às narrativas das crianças, com seus nomes fictícios, escolhidos por elas durante o diálogo com as mulheres no Círculo Epistemológico de Cultura (CEC).

\section{NARRATIUAS}

\subsection{NARRATIUA I: "NO INTERIOR, A GENTE TEM BASTANTE LUGAR PRA BRINCAR"}

Para Arenhart (2007), a criança é identificada, em qualquer parte do mundo, pela idade e pelo brincar. Quando se faz alguma referência às brincadeiras, logo a mente nos reporta ao tempo de criança ou às próprias crianças. As brincadeiras são um jeito próprio das crianças de se relacionarem entre si, com os adultos, com a natureza e com a totalidade do entorno. Essa relação entre ser criança e brincar foi evocada durante a pesquisa de campo nas primeiras palavras pronunciadas pelas crianças ao serem questionadas sobre o que é ser criança camponesa.

Em suas representações, elas expressaram como se compreendem enquanto crianças camponesas, demarcando o espaço geográfico e externando sentimentos de liberdade em vivenciar o lúdico, como disse Luci: "[...] brincar em longos espaços sem ter tanto medo como na cidade. Ver os animais em uma vida tranquila, sem estar presos ou amarrados em correntes." Davi Luís, por exemplo, disse: "Eu acho legal. [...] comparar com os meninos da cidade, 
eu tenho mais liberdade. Eu também gosto [...] [quando] eu quero descansar, lá de baixo da casa, onde tem uma sombra." Nataly disse: "[...] gosto de morar na roça porque parece que, na cidade, não tem onde brincar. Tem mais carro e coisa, e, lá no interior, a gente tem bastante lugar pra brincar." Amaralinda descreve os espaços que a natureza oferece para realizar suas brincadeiras: "[...] é brincar na terra, é brincar na chuva, ir ao rio, pescar no açude, subir em árvores, comer fruta do pé [...]" (informações verbais). É verdadeira a afirmação: "[...] para cada criança, a infância só acontece uma vez, e é sempre agora." (SILVA, 2003, p. 49).

Essas narrativas sobre o ser criança camponesa mostraram um cotidiano de intensa relação lúdica com o ambiente. Diz Silva (2003, p. 145): "[...] brincar é de fundamental importância para o fortalecimento das relações sociais, para construir conhecimento, para expressar emoções." Também observamos nos documentos do MMC que, desde o início do século XXI, as mulheres camponesas vêm estudando e repensando a organização do entorno de suas casas, tendo como horizonte o projeto popular de agricultura camponesa agroecológica. Elas, entre estudo e troca de experiência, trabalho e luta, forjaram práticas educativas que ganham forma na recuperação, produção e melhoramento de sementes crioulas; na recuperação e preservação das plantas e ervas medicinais, frutíferas e nativas; na produção diversificada; na proteção e reaproveitamento da água; na reeducação alimentar; e na luta por políticas agrícolas para a agricultura familiar camponesa (ASSOCIAÇÃO DE MULHERES TRABALHADORAS RURAIS DA REGIÃO SUL DO BRASIL, 2008).

Esse modo de organizar o espaço da produção diversificada passa a ser chamado pelas mulheres camponesas de quintal produtivo agroecológico, referindo-se às variedades preservadas e cultivadas no entorno da casa. Essa prática educativa em construção envolve opção, decisão, resistência e luta cotidiana. Também é possível identificar aspectos em comum entre os quintais produtivos agroecológicos que vêm sendo organizados pelas mulheres camponesas do MMC e a agrofloresta para crianças, experiência realizada por Nuttall (1999, p. 27): 
[...] uma agrofloresta para crianças, além de ser uma horta que produz alimento, tem um elemento adicional: nela há sinais de brincadeiras. Existem pilhas de madeira e pedras, poças de lama, pequenas cercas, locais secretos, pontes, talvez um espantalho e, sem dúvida, coisa que gente grande não vê.

Arenhart (2007, p. 42) acrescenta: "[...] a brincadeira concentra aquilo que é característico das crianças: imaginação, criação, transgressão, fantasia, podendo ser reconhecida nelas a forma pela qual experimentam a cultura, ao mesmo tempo em que a produzem." Assim, também observamos durante a pesquisa que as crianças camponesas, ao acompanharem suas mães no trabalho produtivo e na luta no MMC, apropriam-se do conteúdo do Movimento. A narrativa de Elza é reveladora da imaginação das crianças, que transformaram a luta do MMC em brincadeira enquanto acompanhavam a avó na colheita de amendoim:

No meu tempo de criança, meio que nós brincava de boneca com essas abóboras. Mas não falei nada, disse: "Essas aí é pra vocês brincar", e continuei colhendo amendoim. [...] me surpreendi quando vi Olga pegar uma abóbora e imitar um microfone e falar para os pés de amendoim como se tivesse muita gente. Depois, ela e Eloisa começaram a fazer entrevista. Diziam: "Você sabe que pé é este? Esse pé é um pé de gergelim. [...] Minha vó usa pra pôr em cima das bolachas. [...] Espere um pouco". E gritavam: "Vó, pra que é bom o gergelim?". Daí eu explicava, e elas continuavam a fala delas. (Elza, informação verbal).

A partir de um olhar mais atento percebemos nas brincadeiras e na imaginação das crianças as lutas de suas mães-mulheres militantes. Enquanto a avó brincava de boneca com as abóboras, essas meninas transformaram as abobrinhas em microfones, o amendoim em multidão, o mais interessante: elas se colocavam como líderes. Nesse episódio, podemos abstrair que aí provavelmente está implícita a divisão do trabalho por sexo, quando se ensina para a "meninasmulheres" (SILVA, 2002) o papel de cozinhar, cuidar, limpar, lavar e obedecer. Essas crianças crescem tendo outra concepção do ser mulher na sociedade. 
Revelaram na brincadeira e no diálogo com a avó aspectos importantes da prática educativa de alimentação saudável; além de identificar o gergelim entre os vegetais e de saber como pode ser consumido. Nesse sentido, conforme disse Nuttall (1999, p. 8): "Elas aprendem como as florestas são importantes, como nós as utilizamos e o que elas necessitam para sobreviver."

Os quintais produtivos agroecológicos expressam uma identidade, um modo de vida, uma relação de complementaridade entre o ser humano e a natureza. Nessa perspectiva, as crianças podem "[...] experienciar o contato com elementos de seu ambiente natural - os animais e plantas, o solo, o fluxo da água e o vento, o sol, as estações etc. Além de criar conexões entre crianças e a terra." (NUTTALL, 1999, p. 27). O depoimento de Flor de Lins indica que no quintal produtivo agroecológico de sua mãe e de seu pai tem "Feijão, arroz, carne, tem couve, salsinha, repolho e também cebola, flores bonitas, cobrinhas, também tem gengibre, tem bichinho [...] Tem terra pra brincar, tem balanço, tem rede, tem chuva pra molhar as plantinhas e também tem frutas saudáveis." (informação verbal). Convém esclarecer que, quando se refere à carne, Flor de Lins faz menção a uma planta chamada ora-pro-nóbis, ${ }^{4}$ a qual é rica em proteína, ou aos animais criados para o consumo.

As crianças revelaram que conhecem e sabem identificar plantas e que no quintal produtivo agroecológico há espaço para brincar. Ao acompanhar suas mães no trabalho e na luta no MMC, as crianças aprendem e ensinam. Como disse Freire (2014, p. 96): "mulheres e homens [...] se educam em comunhão, mediatizados pelo mundo."

\footnotetext{
4 Ora-pro-nóbis é uma planta originária do continente americano muito cultivada na região Sudeste do Brasil e muito usada na culinária. É chamada de carne vegetal, porque possui muita proteína, vitaminas A, B, C, fibras, ferro e fósforo. Bom para o funcionamento do intestino e aumento da imunidade. Pode ser usada como salada, chá, refogados, sopa, panqueca e outros (MOVIMENTO DE MULHERES CAMPONESAS EM SANTA CATARINA, 2015).
} 


\subsection{NARRATIUA II: “TEMOS QUE CUIDAR DO MEIO AMBIENTE”}

As crianças camponesas externaram com intensidade sua preocupação em relação à natureza e revelaram um sentimento de cuidado e sensibilidade no que diz respeito à preservação do ambiente. Guerreiro expressa sua concepção e comprometimento: "Temos que cuidar do meio ambiente, porque sem o meio ambiente não podemos ser nada, nada. ambiente é o início de tudo [...]" E acrescentou, fazendo referência às mulheres organizadas no MMC: "Eu sei que elas são defensoras do meio ambiente, que nem eu. Elas são trabalhadoras, lutadoras, [...] e isso me chama atenção. Elas são mulheres fortes." (informações verbais).

Nessa linha de pensamento, Guerreiro (informação verbal) nos adverte que, no aspecto ambiental, devemos estar em luta permanente, pois nem todos conseguem perceber a necessidade de preservar e conservar a biodiversidade. Podemos intuir que as mulheres camponesas do MMC percebem as diferentes concepções que, no cotidiano, revelam a contradição entre capital e trabalho. Nesse contexto, para assumir a luta pela preservação ambiental, as mulheres precisam ser corajosas, pois se trata de implementar a partir de seu cotidiano relações de igualdade alicerçadas nos princípios da vida, da solidariedade e da complementaridade. Daí que, no MMC, as mulheres vêm estudando e construindo um dos caminhos que se contrapõe ao capital, que é a luta pela agroecologia como modo de vida, assumida no conjunto da luta dos povos camponeses ${ }^{5}$ em todo o mundo. De fato,

[...] para o Movimento de Mulheres Camponesas (MMC), a agroecologia é um modo de vida. Vai além de uma forma de produção, buscar a harmonia nas relações dos seres humanos entre si e com a natureza, produzindo e reproduzindo a vida, preservando e multiplicando a biodiversidade. (CINELLI; SANTOS, 2015, p. 11).

\footnotetext{
5 La agroecología fue elegida como "modo de vida que recupera todo lo que hemos perdido, una conexión con los saberes ancestrales", rescatalos mercados locales, saberes de las comunidades, pone en discusión los precios, fomenta el intercambio y eltrue que como modelo económico de una economía social y solidaria basada en la sustentabilidad, redistribución y reciprocidad (LÁ VIA CAMPESINA, 2013).
} 
No campo, lugar de vivência e trabalho, crianças e adultos estão permanentemente interagindo, trabalhando e lutando pela construção da vida. Na visão de Leite (2002, p. 66), "[...] a criança camponesa brinca e relacionase com seus pares, ao mesmo tempo que convive com seus outros papéis e funções dentro da comunidade familiar no cumprimento de suas tarefas." As crianças não ficam alheias aos trabalhos de seus familiares; pelo contrário, acompanham o processo de criação das diversas experiências e atividades junto com a mãe, o pai e os irmãos, brincando, observando e envolvendose em diferentes trabalhos, como a preparação do solo para o plantio das sementes crioulas, o manejo das plantas medicinais, a produção de alimentos saudáveis e/ou a criação de animais. As mulheres "possuem uma ciência de combinar a produção vegetal e a criação animal o ano todo." (MOVIMENTO DE MULHERES CAMPONESAS EM SANTA CATARINA, 2008, p. 29). É mister salientar que, no MMC, essas práticas educativas transformaram e continuam transformando hábitos, atitudes e espaços, como expressou Marilize Beatriz (informação verbal):

Tinha uma época que nossa horta virava um deserto. Não dava nada, calor, falta de chuva [...] A gente aprendeu a manejar e fazer com que nossa horta fique produtiva o ano inteiro. Que a gente tenha algo para oferecer, mostrar pra família, amigas, o nosso serviço, o que a gente faz no Movimento. Eu vejo assim: se você quer ter saúde, a principal coisa é você mostrar na mesa como você consegue trazer do trabalho, do dia a dia, possa tá oferecendo pra família saúde e qualidade de vida [...]

O depoimento de Marilize Beatriz mostra que, a partir do processo formativo no MMC, ela pôde reorganizar a produção e transformar sua horta em um quintal produtivo agroecológico. Nesse sentido, "A agroecologia se constitui em uma ferramenta estratégica de resistência das camponesas e camponeses e de proposição para um projeto de agricultura camponesa agroecológica." (CINELLi; SANTOS, 2015, p. 11). 
Observamos que as crianças gostam de brincar e fazer descobertas no quintal produtivo agroecológico. Assim, quando acompanham as mulheres militantes em encontros de estudo ou mobilizações, as crianças estão sempre se relacionando com temas, episódios e situações de luta: "[...] a criança constrói e vive o hoje, vive a sua história. Ela vive a história de sua família, da sua comunidade, da humanidade, e seus brinquedos são 'um mundo de diálogo simbólico' entre elas e o povo." (LEITE, 2002, p. 66).

Essa presença das crianças na militância representa um traço fundamental da cultura da família camponesa. Trata-se de um reflexo da própria realidade do campo, onde a criança não permanece sozinha em casa, mas, sim, sempre está em companhia da mãe. Há uma preocupação com o cuidado e a proteção de seus filhos, já que a vida cotidiana nesses meandros é vivida à luz das tarefas domésticas e laborais no campo.

Em diálogo sobre o quintal produtivo agroecológico, Maikeli disse que é o "[...] lugar que tem plantas medicinais, alimento e tem árvores." Na visão de Heitor, "[...] os quintais fazem bem para as árvores e pra nós." (informações verbais). Já Rosa (informação verbal) explicou como "[...] os pinus sugam a água":

Porque, se o pinus for plantado, perto dele não dá pra plantar mais nada. Por [essa] causa, sempre quando a plantinha nasce, o pinus não deixa ela crescer. Ele tem um cheiro muito forte e ele suga toda a água da terra. [...] por isso que falam que, quando você está num lugar assim, cheio de pinus, elas falam que você está num deserto verde.

Como podemos perceber, as crianças camponesas expressam o que vêm aprendendo com suas mães militantes. Seus depoimentos trazem para o debate a problemática dos monocultivos, cujo objetivo, segundo as reflexões e estudos das mulheres do MMC, é servir ao capital transnacional. Essa prática de fazer agricultura elimina a biodiversidade, constituindo-se, para o MMC e todos os povos do campo, uma luta de enfrentamento ao modelo capitalista e convencional de agricultura. De acordo com Carvalho (2003), o capital impõe à vida dos camponeses os seguintes aspectos e determinações: imposição da produção de monocultivos, de sementes híbridas e de transgênicos; aceitação 
da ideologia consumista, imposta brutalmente pela mídia; e consumo de alimentos industrializados e padronizados abandonando a diversidade regional. Observamos que as crianças conseguem ler e interpretar a luta das mulheres, apontando os prejuízos do deserto verde para a biodiversidade, e isso implica lutas estratégicas.

Para Carvalho (2003, p. 97), essas grandes corporações internacionais subjugaram a agricultura impondo profundas "[...] mudanças, tanto na matriz tecnológica e na forma de organização da produção, quanto na matriz de consumo alimentar familiar." As consequências envolvem não apenas a desorganização do modo de vida camponesa como também a perda da identidade cultural, social e ética (CARVALHO, 2003).

É nesse contexto contraditório de dominação e luta e de opressão e libertação que as mulheres camponesas defendem e desenvolvem, em suas unidades de produção, a agroecologia calcada, entre outros princípios, na ética, no comprometimento, na solidariedade e na preservação dos bens naturais para as futuras gerações. Assim, fazem do cotidiano e do trabalho o enfrentamento ao capital, por exemplo, no que diz respeito ao combate dos transgênicos, quando realizam a recuperação e produção de sementes crioulas, plantas medicinais, pomares, jardins, criação de pequenos animais, entre outras práticas de produção de alimentos saudáveis. Toda essa luta política é realizada tendo como elemento emancipatório a luta em oposição, resistência e enfrentamento ao patriarcado. Ou seja, quando saem de casa, é para se organizar em torno da construção de novas relações de igualdade de gênero e defesa do meio ambiente. São mulheres que ao mesmo tempo trabalham e participam dos processos formativos e de luta política no MMC. Elas buscam implementar outras matrizes produtivas e, consequentemente, outros hábitos e valores construídos no interior das suas famílias.

Quanto aos monocultivos, ainda, podemos destacar alguns aspectos presentes nos depoimentos das crianças evidenciados nos estudos realizados por Paulilo e Matias (2016, p. 223): “Um dos problemas do reflorestamento é sua grande exigência de água, tanto para o desenvolvimento das florestas de pinus e eucaliptos como para o processo de produção de celulose." Pinha, 
participando com a mãe e a vovó, compreendeu essa realidade: "[...] por isso que falam que, quando você está num lugar assim, cheio de pinus, elas falam que você está num deserto verde" (informação verbal), pois ali outras espécies de vida não sobrevivem.

Paulilo e Matias (2016) destacam algumas consequências negativas da invasão dos monocultivos de pinus e eucaliptos na vida camponesa, como a perda da diversidade de vegetais e animais, o desequilíbrio ambiental e a inviabilidade da convivência entre o gado e o reflorestamento, porque os pinus e os eucaliptos impedem o crescimento de vegetação rasteira, necessária à alimentação dos animais, e expulsam os camponeses da terra, gerando desemprego. Todos esses episódios e ocorrências reduzem a disponibilidade de água essencial para o desenvolvimento das espécies, criando um "deserto de florestas" (PAULILO; MATIAS, 2016). As crianças confirmaram o que disse Pinha: "[...] os monocultivos são 'desertos verdes'." (informação verbal).

Durante a pesquisa de campo, percebemos que as crianças tomam consciência dos problemas que atingem e põem em risco a agricultura camponesa familiar. Essa percepção brota das práticas educativas das mulheres-mães organizadas no MMC, que debatem sobre as consequências dos monocultivos. A esse respeito Freire (2014, p. 54) nos adverte que "Quanto mais as massas populares desvelam a realidade objetiva e desafiadora sobre a qual elas devem incidir sua ação transformadora, tanto mais se 'inserem' nela criticamente." Com efeito, as crianças do campo, inseridas em um espaço de grande biodiversidade, compreendem, em diálogo com suas mães e familiares, conforme já mencionamos, os meandros da luta feminista camponesa. Em síntese, nos apelos de suas falas, elas parecem compreender os interesses de classe que subjazem às práticas educativas do MMC, além das lutas de gênero, étnico-raciais, geracionais e ambientais. Tudo isso pode ser sintetizado a partir da seguinte expressão evocada na síntese das narrativas de alguns depoimentos: "[...] temos que cuidar do meio ambiente para as futuras gerações." (informação verbal). 


\subsection{NARRATIUA III: “EU FAÇO, MAS NÃO TUDO”}

Leite (1997, p. 77) constatou que as crianças, "[...] desde bem pequenas, realizam as tarefas ao lado dos mais velhos: ajudam suas mães nas atividades domésticas e seus pais em serviços variados." No CEC as crianças expressaram diferentes opiniões sobre o trabalho. Heitor disse: "[...] crianças não podem trabalhar"; Eloise falou: "Eu ajudo a mãe. [...] criança é pra brincar e estudar. Aproveitar, enquanto é criança, porque depois de adulto tem que trabalhar." Maikeli problematizou: "Dependendo do trabalho [eu faço]." Davi Luís disse que ajuda a família no trabalho "[...] de casa e no serviço [...]" Em seguida ponderou "[...] trabalho pesado assim não é pra criança." Lucas relatou: "Eu ajudo fazer as coisas lá fora." (informações verbais). Nesse caso, o "serviço" e "as coisas lá fora" significam trabalhos no entorno da casa, como tratar o gato, o cachorro, as galinhas e outros animais; abrir o portão para os bezerros; regar as plantinhas; colher verduras e frutas; "cuidar" de irmãos menores, entre tantos outros trabalhos que fazem parte da vida camponesa.

Muitas vezes, a mãe vai para a roça tratar os animais ou ordenhar a vaca e precisa levar seu filho junto, porque não tem com quem deixá-lo; como disse Leite (1997), no campo, as crianças estão permanentemente junto com os adultos. "Até o bebê, que ficava numa gamela, não escapava da roça. Enquanto os pais trabalhavam na lavoura, Adélia e os outros filhos brincavam ao redor, muitas vezes, já com uma enxada pequena e, claro, sob o olhar vigilante da mãe." (AUED, 2007, p. 87). Enquanto brincavam, um cuidava do outro, como se quisessem ajudar a mulher-mãe, que vai "correndo" fazer as inúmeras jornadas de trabalho. Desse modo, essas crianças crescem em um ambiente de trabalho e responsabilidades principalmente ao vivenciarem cotidianamente a árdua tarefa das mães na lida com o árduo trabalho do campo, o trabalho doméstico e as demais tarefas familiares.

Arenhart (2007) esclarece que as desigualdades sociais, próprias da sociedade capitalista, impõem sobre as crianças camponesas a necessidade de assumir o mundo do trabalho para sobreviver. Aued e Vendramini (2009, p. 41), em seus estudos sobre o trabalho infantil em Santa Catarina, constataram 
que as crianças camponesas trabalham "[...] nas atividades: [de] fumicultura, colheita de erva-mate, maçã, plantio de tomate, cebola, cerâmica, olarias, calçados, serviços domésticos, entre outras."

É mister destacar que o trabalho, para as crianças do CEC, tem outra dimensão, de natureza educativa, que envolve uma gama de aprendizagens sociais, coletivas e políticas, como o brincar, o aprender e o fortalecimento das relações familiares. Quanto a esse aspecto, Guerreiro relata que "[...] lava a louça, faz pudim..., bolo [...]" (informação verbal), informando que o bolo de morango servido no lanche fora feito por ele e por sua mãe. É importante esclarecer que faz parte das práticas educativas do $\mathrm{MMC}$, sempre que as mulheres se reúnem, levar lanches ou ingredientes para as refeições, sementes crioulas, mudas e plantas medicinais para compartilhar e artesanato para trocar ou vender. Observamos que Guerreiro está aprendendo com sua mãe a cozinhar. Esse trabalho, até pouco tempo atrás, era dado às meninas. No entanto, no MMC, as mulheres trouxeram para o debate a divisão do trabalho por sexo, buscando problematizar essa questão. Desse modo, o movimento trouxe para as práticas educativas entre as mulheres e as crianças a problemática sobre o papel que as mulheres exercem na sociedade e o enfrentamento e a superação da educação patriarcal (SAFFIOTI, 2015). Esse tipo de educação passa a ser compreendido como construção social, mas que pode ser resignificada e transformada mediante as práticas educativas que se engendram na vida cotidiana nas relações sociais entre as mulheres, a família e as crianças. De tudo isso resulta a necessidade de ousar, organizar e lutar (MOVIMENTO DE MULHERES AGRICULTORAS, [198?], p. 7).

Observamos que as relações patriarcais, em muitos casos, continuam a existir, porém elas não são mais concebidas pelas mulheres camponesas como naturais. Nas representações das crianças do CEC, pôde-se perceber que há uma educação para o assumir coletivo, na qual o trabalho doméstico é ensinado para meninos e meninas em diálogo com o companheiro. Guerreiro disse: "[...] as mulheres trabalham fora. [...] trabalham aqui no Movimento, aí [...] os homens têm que cuidar da casa." Durante a realização do CEC, outras crianças afirmaram que "[...] as mulheres deixam prontas todas as coisas para 
os homens e ainda os homens reclamam. Fazem comida, lavam roupa, limpam a casa [...]" (informações verbais).

São duas representações: uma trata da luta pela divisão de trabalho na qual o homem é quem toma conta da casa, do trabalho doméstico, do cuidado dos filhos, e a mulher é militante e trabalha fora, o que não significa ausência de conflitos. Pelo contrário, há sempre impasses, dificuldades e barreiras se confrontando permanentemente, mas que se apresentam, ao mesmo tempo, como fatores que sinalizam para a existência de uma possível consciência coletiva no que tange à ideia do trabalho compreendido como produção e reprodução material. A outra narrativa nos mostra que a mulher militante convive com as contradições entre o que vem "descobrindo" sobre o seu papel social e a realidade concreta em que está inserida. Ela tem a responsabilidade de, antes de sair de casa, deixar "prontas as coisas" para quem fica, referindo-se ao homem e às crianças. A mulher camponesa militante depara-se com muitos desafios, quais sejam lutar contra a perpetuação do capital e, simultaneamente, romper com as amarras do patriarcalismo, com vistas a romper com as determinações de classe e gênero.

Essas representações não podem ser analisadas ao pé da letra, tendose em vista que as experiências contidas nas narrativas guardam especificidades e heterogeneidades, além de serem contraditórias. Entendemos que fazem parte de vivências em construção e de lutas por superação, para o "ser mais" (FREIRE, 2014). Se assim é, então as próprias relações podem vir a ser modificadas, questionadas e (re)significadas por meio das práticas educativas orientadas por um projeto de vida e de sociedade calcado nas relações de igualdade do ponto de vista de classe e gênero no campo e na cidade.

A participação das crianças nas práticas educativas no $\mathrm{MMC}$ lhes possibilita o aprendizado sobre o sentido da luta do Movimento em torno do feminismo camponês e também sobre os sentidos do trabalho para suas mães e para si próprias. A esse respeito, Heitor disse: "[...] crianças não podem trabalhar [...] Eu também ajudo minha mãe aqui no MMC." (informação verbal). De fato, isso pôde ser constatado durante as atividades realizadas no centro de formação, em que, entre as atividades lúdicas, meninas e meninos também 
se envolvem com as mulheres na organização das místicas e do ambiente de estudo, além de participarem do teatro e de outras atividades.

Isso significa que para entender as crianças camponesas há que se observar o espaço geográfico e social, a condição econômica, cultural e religiosa em que estão inseridas, pois o significado atribuído à criança e ao seu entorno não é uniforme. Considerar o contexto de convivência da criança é necessário para não "[...] dissimular a significação social da infância." (KRAMER; LEITE, 1997, p. 21). Por tudo isso, temos consciência de que a problemática do trabalho das crianças requer de nós maior aprofundamento. Por outro lado, temos que admitir que não permitir que as crianças se envolvam nos trabalhos do campo se torna também um problema, pois, desse modo, crescerão deslocadas das formas de produção e reprodução da vida em que estão inseridas (CALDART; STEDILE; DAROS, 2015).

Evidentemente que aqui não estamos tratando do trabalho na lógica capitalista que o transforma em mercadoria. Caldart, Stedile e Daros (2015, p. 8) defendem que o trabalho como prática educativa é a matriz fundamental para a formação do ser humano "[...] como ser social e histórico, sujeito de práxis." Isso se materializa pelo trabalho, "[...] atividade humana criadora da própria vida humana na sua relação com a natureza, na construção do mundo e de si mesma." (CALDART; STEDILE; DAROS, 2015, p. 8). Nesse sentido, a escola e os processos formativos nos movimentos sociais populares têm a tarefa de pensar o trabalho que se transforma em luta concreta para melhorar as condições de vida e construir relações de igualdade.

Isso significa dizer que a prática é, ao mesmo tempo, teoria, pois implica entendimento prático do que fazer e de como fazer. A concepção de educação no MST envolve a "[...] luta social, organização, coletividade, terra, trabalho e produção, cultura e história como matrizes formativas fundamentais para a vida." (CALDART; STEDILE; DAROS, 2015, p. 207-208, grifo do autor). Isso mostra o esforço do Movimento Sem Terra em construir uma escola para crianças, adolescentes, jovens e adultos próxima "[...] da vida real, do trabalho, da luta." (CALDART; STEDILE; DAROS, 2015, p. 5). 
Nesse contexto a questão do trabalho foi sendo incorporada como valor cultural e educativo entre os camponeses. Contudo, em famílias ou regiões empobrecidas, as dificuldades econômicas ainda exigem das crianças responsabilidades com o trabalho remunerado. Silva (2003) concluiu que as crianças gostam de brincar, entretanto "[...] o cansaço imposto pelas obrigações laborais inibe os impulsos lúdicos, o desejo de brincar, impondo assim constrangimentos, preocupações e responsabilidades prematuras do trabalho." (SILVA, 2003, p. 292). Além disso, verificou-se que as meninas têm maior responsabilidade com trabalho doméstico do que os meninos:

As meninas demonstraram ao mesmo tempo resignação e indignação pelo fato de os meninos, apesar da vida dura, terem mais oportunidade aos jogos e brincadeiras (futebol, andar pelo mato, etc.) restando para elas apenas brincar de bonecas e a responsabilidade do trabalho doméstico. (SILVA, 2003, p. 242).

autor mostra que, entre as brincadeiras, reproduz-se a divisão do trabalho por sexo, que, no $\mathrm{MMC}$, vem sendo assumida como uma luta contra o patriarcalismo. Tanto Silva (2002, 2003) quanto Arenhart (2007) e Caldart, Stedile e Daros (2015) mostraram que o trabalho concebido como atividade social faz parte da vida da criança camponesa e precisa ser reconhecido e valorado. Arenhart (2007, p. 135) esclarece que "[...] as crianças trabalham e isso não chega ser um problema para o direito da infância, desde que o tipo de trabalho que realizam não as aliene da condição de sujeito e de crianças." A autora concebe o trabalho na perspectiva marxista como atividade criadora, construtora e transformadora da realidade, reconhecendo a dimensão humana e digna que nele se inscreve (ARENHART, 2007). Essa concepção se contrapõe aos ditames da exploração do trabalho na sociedade capitalista. 


\subsection{NARRATIUA IU: CRIANÇA CAMPONESA LEUANTA “ÀS 6H 20MIN PARA IR DE ÔNIBUS PRA ESCOLA"}

Para Amaralinda, ser criança camponesa é: "Ajudar nas atividades da roça e da casa. [...]. Levantar às 6h20min para ir de ônibus pra escola. [...] tocar as vacas do pasto, cuidar dos animais, brincar com os bezerrinhos, com pintinhos, ajudar a arrumar os produtos pra feira e pro PAA [Programa de Aquisição de Alimentos]" (informação verbal). Ela demonstrou uma relação de responsabilidade com o trabalho realizado em prol do coletivo familiar; trabalho esse que exige organização e disciplina.

São particularidades que influenciam a vida e a realidade de Amaralinda, não sendo, portanto, um fato isolado, mas, sim, a realidade da maioria das crianças camponesas. Ela é uma criança que brinca, estuda, trabalha, luta e aprende, mostrando-se inserida nos trabalhos, pois participa e conhece a lida da mãe e do pai. Ademais, sabe das políticas públicas do $\mathrm{PAA}^{6}$ e tem contato com os consumidores da feira. Nessa mesma direção, Luci também se posicionou sobre a relação entre produção e consumo: "[...] no campo não precisa comprar muitos alimentos, pois temos onde produzir com carinho o alimento que precisamos [...] Temos frutas e alimentos puros, sem ter agrotóxicos, na hora de ser levado pra vender." (informação verbal).

As crianças mostraram que sabem e conhecem a vida de trabalho de seus familiares. De acordo com Leite (1997), elas se envolvem e vivenciam, com os adultos, diferentes aspectos de seu viver e, quando há diálogo, podem construir uma relação de sujeitos. A autora chama atenção para a necessidade de compreender a criança camponesa em seu meio sociocultural, pois é a partir de seu entorno que ela interpreta o ser criança camponesa, o que fica corroborado no campo deste estudo. De fato, a criança camponesa vivencia no cotidiano as experiências laborais de seus pais, em especial de suas mães que vivem tripla jornada de trabalho. Isso acontece porque as crianças estão sempre perto das

6 O Programa de Aquisição de Alimentos (PAA) foi instituído em 2003 e é uma política pública de articulação entre produção, comercialização e consumo com "[...] duas finalidades principais: promover o acesso à alimentação e incentivar a agricultura familiar (CRUZ; VIEGAS; VIANA, 2010, p. 1). 
mães e dos pais, contribuindo, de algum modo, na realização de algumas tarefas laborais. Percebemos que as mães militantes têm preocupação com o conhecimento, estudo e lazer, cultura das crianças. E Conte (2014) observou que as crianças camponesas estão presentes no trabalho, mas suas mães e pais têm compreensão que precisam tempo para o lazer e estudos. Elas socializam esse aprendizado na escola, fazendo a diferença, como relatou Rosa:

[...] porque, quando a gente tem algum trabalho de aula, dá pra fazer uma filmagem. A professora pede, às vezes, grãos, sementes; a gente tem e tira foto. [...] Tem gente que estuda lá no Simoneto [Linha do interior] que não tem. É tudo comprado. [...] Esses dias, a professora pediu pra tirar foto de animais, cabra, essas coisas. Daí, lá em casa não tinha. Daí a gente foi lá na tia Maria, tirou foto das cabras e de tudo lá. (informação verbal).

A narrativa de Rosa é reveladora de uma educação cuja escola trabalha aspectos das relações vividas no campo. A convivência com os pequenos animais e a integração com as comunidades vizinhas fazem parte das tarefas das crianças na escola de Rosa. A liberdade lhe proporciona a autonomia de buscar conhecimentos a partir da vida no campo. Essas aprendizagens de liberdade são compartilhadas com seus colegas na sala de aula. Nesse caso, a liberdade também é indicadora de aprendizagens sociais pensadas a partir de outros valores éticos e estéticos presentes na educação camponesa, como a solidariedade, a criatividade e a cooperação.

Não há dúvidas de que essas crianças vão aprendendo a ser livres à medida que aprendem a ser solidárias. E, no campo, a solidariedade se amplia. Passa pela iniciativa, pelo contato com os animais e plantas, pelo ato de pisar a terra e interagir com a natureza, pelas relações de vizinhança e comunidade, pela preservação ambiental. Quando Rosa conta que tiraram fotografia de "tudo lá", está expressando, com seu jeito simples, que tiraram fotografia das cabras, do potreiro/piquete cercado com pastagem e do galpão, que é a área coberta para abrigo das cabras e de outros animais domésticos. Ela está afirmando algo de grande importância na sua vida. Isso Rosa leva e socializa com seus colegas na escola. Esse compartilhar carrega consigo sua 
visão de campo, sua concepção da vida que Rosa vive e aprende no espaço do movimento, pois consegue perceber que existem outras crianças que moram na área rural, mas não tem aquilo que é característico do campo, como sementes, animais, entre outros.

Nesse percurso educativo, o cotidiano das crianças e das mulheres também é um terreno propício para o enfrentamento dos preconceitos. Em se tratando do campo, um dos preconceitos reproduzidos historicamente está relacionado à ideia de que o campo é o lugar do "atraso", lugar de pouca perspectiva de vida. Pois há uma construção que caminha na direção contrária, em que tudo aponta para a cidade como o ideal para a vida humana. Há escolas e Escolas! No caso de Rosa, na sua escola há espaço para problematizar tais concepções, pois as próprias crianças levam outros olhares para aquele espaço considerado formal, o que não é comum na maioria das instituições educacionais.

As narrativas fazem um contraponto a essa construção do imaginário social que reproduz uma ideia positiva/aumentativa da cidade e negativa/ diminutiva em relação ao campo. E essa é inegavelmente uma das contribuições do MMC para a educação formal. Cabe, ainda, dizer que o processo formativo no MMC traz consigo aspectos de uma prática educativa que vem rompendo com imposições da educação patriarcal. Marilize Beatriz, mãe de João Vitor e Davi Luís e militante do Movimento, disse que "[...] a gente consegue [...] distribuir as tarefas dentro de casa com as crianças." (informação verbal). Suas representações sobre a mulher, a casa, os filhos, o trabalho não eram assim no passado mais recente. Ao participar do MMC, ela foi repensando o ser mulher camponesa e as relações com os filhos, o companheiro e os avós e construindo uma educação libertadora.

A gente vem assim de uma cultura [pausa], eu vejo [...] muita diferença na educação da criança [...] E agora a gente consegue por causa do Movimento. $\bigcirc$ meu filho maior, ali, tem o serviço dele em casa, que ele sabe que tem que fazer mesmo sendo rapaz. [...] Ele sendo criança, ele tem que saber que as coisas não caem do céu como a chuva. A gente tem que trabalhar, tem que lutar. Ele tem que crescer junto nisso. (Marilize Beatriz, informação verbal). 
Marilize Beatriz, militante do MMC, toma nas mãos sua história, identifica as contradições no grupo familiar, as dificuldades entre gerações, a educação patriarcal que receberam, mas, nesse meio, não se cala. Ela toma iniciativa e começa a dar direção para sua vida, exercita com seu grupo familiar outra prática educativa, visando repensar as relações sociais no cotidiano. Nesse sentido, ela, seu companheiro e os dois filhos estão reconstruindo outros conceitos, costumes, atitudes e relações sociais para além da opressão, visando elaborar outras representações de ser homem e de ser mulher em construção; de outro gênero de humano, em suma.

De acordo com Freire (2014, p. 227), “[...] na teoria dialógica da ação, os sujeitos se encontram para a transformação do mundo em colaboração." A prática demonstra que outra concepção de infância camponesa está diuturnamente em processo de construção. Essas crianças revelaram que não estão afastadas das práticas educativas do MMC. $\bigcirc$ que as mulheres estudam e fazem, em termos de práticas educativas, possibilita que as crianças desenvolvam outras formas de ler e interpretar o mundo.

Essas crianças são, de acordo com Perrotti (1990), produtoras de cultura. O autor chama atenção para o fato de que a criança deve ser observada e compreendida agindo em seu contexto, pois há uma tendência de se pensar "na criança recebendo (ou não recebendo) cultura e nunca na criança fazendo cultura ou, ainda, na criança recebendo e fazendo história e cultura ao mesmo tempo." (PERROTTI, 1990, p. 18). Observamos que as crianças camponesas do MMC interagem, estudam, trabalham, lutam e brincam criando e recriando seu modo de vida, lado a lado com os adultos, em um ambiente de diálogo, de ludicidade, de reflexão e de luta. Afinal, o fazer educativo é uma "ação cultural" entendida como prática de liberdade (FREIRE, 2014, p. 145).

Kramer (1997) busca em Paulo Freire a dimensão do ser humano sujeito de sua ação, lembrando ser necessário considerar "[...] adultos e crianças como cidadãos. Criadores de e criados na cultura, produtores da e produzidos na história, feitos de e na linguagem." (KRAMER, 1997, p. 25, grifo do autor). Diante dessas reflexões teórico-empíricas, observamos, enfim, que as crianças camponesas revelam, de maneira insofismável, uma articulação, no âmbito das práticas educativas no campo, entre o tempo de brincar, estudar, 
trabalhar e, juntamente com as mulheres-mães militantes e a família, lutar por um projeto de sociedade de caráter emancipatório e cidadão.

\section{CONCLUINDO PARA RECOMEÇAR: PESQUISANDO, LUTANDO E RESISTINDO}

Esperamos que as contribuições trazidas com esta pesquisa, de relevância pessoal, acadêmica, política e social, possam problematizar as ações do MMC, ao expormos para o debate o processo político-pedagógico das crianças camponesas e suas mães militantes na construção desse movimento autônomo, de gênero, de classe, feminista e camponês. A pesquisa trouxe como destaque nas narrativas das crianças a ideia de que elas estão cientes do papel das mulheres no Movimento e do conteúdo das práticas educativas deste. São práticas que envolvem estudo e luta ou, em outras palavras, teoria e prática. Nas entrelinhas de suas narrativas as crianças camponesas demonstram compreender os princípios da luta política envolvendo gênero, classe, etnia/ raça e geração a partir da perspectiva do feminismo camponês.

Outra constatação digna de destaque diz respeito ao fato de as crianças camponesas se conceberem como parte da natureza e se relacionarem com ela tanto nos trabalhos domésticos quanto nos quintais produtivos agroecológicos. Nesses espaços, misturam-se as brincadeiras, a diversidade de alimentos e os saberes da terra para produção da vida. É nesses espaços de luta e práticas educativas que as crianças vivenciam a sensação da liberdade ao se relacionarem com a natureza: terra, sementes, flores, animais, árvores, sombras, frutas saudáveis e chuva para brincar. Em suma, é por meio das práticas educativas do MMC que as crianças adquirem formação política, aprendem a identificar e a conhecer muitas espécies de plantas e animais, assim como a entender que os direitos são conquistas da luta dos trabalhadores. Quanto aos quintais produtivos agroecológicos, são laboratórios de produção e preservação da sabedoria milenar, do conhecimento herdado e aprendido de geração em geração pela vivência, partilha e reflexão. 
Por fim, a pesquisa aponta que as crianças camponesas expõem as contradições e se posicionam diante do trabalho doméstico e das atitudes e ideias patriarcais advindas dos adultos. Essas representações são indicativo de que algo novo e emancipatório está em curso na construção social da infância camponesa. Suas representações desvelam de forma explícita e implícita expressões de contestação, resistência, ruptura e enfrentamento das questões vividas no cotidiano do MMC. E tudo isso brota em meio a um ambiente que lhes permite educativamente brincar, estudar, trabalhar, ajudar a produzir alimentos saudáveis e estudar. Vale destacar que, em relação ao conceito de ser criança camponesa do MMC, podemos dizer que elas desmistificaram a eterna infância inocente e tosca do campo, sem informação, rude, enfim, "da roça". Antes, pelo contrário, elas demonstram viver uma infância histórica e politicamente situada na realidade da vida do campo, e trabalham, lutam, estudam, brincam e têm responsabilidades e regras a seguir, mediada pelo mundo dos adultos. Há, nessa perspectiva, uma identidade de criança camponesa em construção.

Para finalizar, mas continuando a pesquisar, estudar e lutar, caberia perguntar às crianças por que fazem suas místicas, por que lutam e cantam junto com as mulheres por justiça, contra o patriarcalismo no campo, pelo meio ambiente e em defesa da produção de alimentos saudáveis para todos. Podemos dizer que, com seus imaginários e representações, talvez elas nos respondessem com os versos do grande poeta uruguaio Mário Benedetti (1988), em sua Antologia Poética: "[...] cantamos porque chove sobre o sulco e somos militantes desta vida e porque não podemos nem queremos deixar que a canção se torne cinzas."

\section{REFERÊNCIAS}

ASSOCIAÇÃ O DE MULHERES TRABALHADORAS RURAIS DA REGIÃO SUL DO BRASIL. Mulheres camponesas em defesa da saúde e da vida. Chapecó: [s.n.], 2008. Cartilha.

ARENHART, D. Infância, Educação e MST: quando as crianças ocupam a cena. Chapecó: Argos, 2007. 
AUED, B. W.; VENDRAMINI, C. (Org.). A persistência do trabalho infantil na indústria e na agricultura em Santa Catarina no contexto brasileiro. Florianópolis: Insular, 2009.

AUED, B. W. (Org.). Nossas Histórias. Florianópolis: Insular, 2007.

BENEDETTI, M. Por que cantamos. In: Antologia poética. Rio de Janeiro: Record, 1988.

$\mathrm{BOAL}, \mathrm{A}$. Jogos para atores e não-atores. Rio de Janeiro: Civilização Brasileira, 2007.

CALDART, R.; STEDILE, M. E.; DAROS, D. (Org.). Caminhos para transformação da escola 2: agricultura camponesa, educação politécnica e escolas do campo. São Paulo: Expressão Popular, 2015.

CARVALHO, H. M. (Org.). Sementes: patrimônio do povo a serviço da humanidade. São Paulo: Expressão Popular, 2003.

CINELLI, C.; SANTOS, G. R. S. Feminismo e agroecologia. Revista Camponesa, Chapecó, n. 3, p. 7-13, nov. 2015.

CONTE, I. I. O processo educativo da luta e do trabalho das mulheres: via campesina no Brasil, UNORCA/UNMIC e CONAMI no México. 2014. 197 p. Tese (Doutorado em Educação)-Universidade Federal do Rio Grande do Sul, Porto Alegre, 2014.

CRUZ, K. C. M. S.; VIEGAS, G. L.; VIANA, C. A. S. O acesso da agricultura familiar brasileira às políticas públicas: a evolução do Programa de Aquisição de Alimentos. [S.l.]: Companhia Nacional de Abastecimento, 2010. Disponível em: <https://goo.gl/EC5ocV>. Acesso em: 22 maio 2017.

FREIRE, P. Pedagogia do Oprimido. 50. ed. São Paulo: Saraiva, 2014.

KRAMER, S.; LEITE, M. I. (Org.). Infância: fios e desafios da pesquisa. 2. ed. Campinas: Papirus, 1997.

LAMARE, F. F. "Ser criança" no Brasil: concepções e disputas na sociedade de classes. Revista Trabalho Necessário, Rio de Janeiro, n. 24, p. 145-175, maio/ago. 2016.

LANG, A. B. da S.G.; CAMPOS, M. C. S. S; DEMARTINI, Z. de B. F. História Oral, Sociologia e Pesquisa: a Abordagem do CERU. São Paulo: Humanitas, 2010. 
LÁ VIA CAMPESINA. Organizaciones se unen para fortalecer lucha por la soberanía alimentaria. Hahare, Zimbábue, 09 set. 2013. Disponível em: <https://goo.gl/kqn9SF >. Acesso em: 23 out. 2017.

LEITE, M. I. F. P. Brincadeiras de menina na escola e na rua: reflexões da pesquisa no campo. Cadernos Cedes, Campinas, n. 56, p. 63-80, 2002.

LEITE, M. I. F. P. O que falam de escola e saber as crianças da área rural? Um desafio da pesquisa no campo. In: KRAMER, S.; LEITE, M. I. F. P. (Org.). Infância: fios e desafios da pesquisa. 2. ed. Campinas: Papirus, 1997. p. 73-96.

MINAYO, M. C. S. O desafio do conhecimento: pesquisa qualitativa em saúde. 12. ed. São Paulo: Hucitec, 2014.

\section{MOVIMENTO DE MULHERES AGRICULTORAS. A Mulher Agricultora.}

Chapecó: Montagem de distribuição Serviço de Apoio e Informação, [198?]. Cartilha para os grupos de Base $n^{\circ} 1$.

MOVIMENTO DE MULHERES CAMPONESAS EM SANTA CATARINA. Relatório da oficina de saúde integral. Tema: plantas medicinais e princípio ativo. Irati, 05 maio 2015.

MOVIMENTO DE MULHERES CAMPONESAS EM SANTA CATARINA. Uma história de organização, lutas e conquistas. Santa Catarina: Gráfica Rota, 2008. Cartilha.

MUYLAERT, C. J. et al. Entrevistas narrativas: um importante recurso em pesquisa qualitativa. Revista da Escola de Enfermagem da USP, São Paulo, v. 48, n. 2, p. 193-199, 2014. Edição Especial. Disponível em: <https://goo. gl/4Fvzir >. Acesso em: 05 abr. 2014.

NUTTALL, C. Agrofloresta para crianças: uma sala de aula ao ar livre. Lauro de Freitas: Instituto de Permacultura da Bahia, 1999.

PAULILO M. I. S.; MATIAS, I. A. A. Mulheres e eucaliptos. In: PAULILO, M. I. S. (Org.). Mulheres rurais: quatro décadas de diálogo. Florianópolis: Ed. UFSC, 2016. p. 221-228.

PERROTTI, E. A criança e a produção cultural. In: ZILBERMANN, R. (Org.). A produção cultural da criança. Porto Alegre: Mercado Aberto, 1990.

ROMÃO, J. E. et al. Círculo epistemológico círculo de cultura como metodologia de pesquisa. Educação \& Linguagem, São Paulo, n. 13, p. 173-195, jan./ jun. 2006. 
SAFFIOTI, H. A mulher na sociedade de classes: mito e realidade. 3. ed. São Paulo: Expressão Popular, 2013.

SAFFIOTI, H. Gênero, patriarcado, violência. 2. ed. São Paulo: Expressão Popular, 2015.

SAFFIOTI, H. Prefácio. In: SILVA, M. A. M. (Org.). Errantes do Fim do Século. São Paulo: Ed. Unesp, 1999. p. 8-9.

SILVA, M. R. Recortando e colando as imagens da vida cotidiana do trabalho e da cultura lúdica das meninas-mulheres e das mulheres-meninas. Cadernos Cedes, Campinas, n. 56, p. 23-52, 2002.

SILVA, M. R. Trama Doce-amarga (exploração do) trabalho infantil e cultura lúdica. Ijuí: Ed. Unijuí, 2003.

Recebido em 22 de novembro de 2017 Aceito em 25 de abril de 2018

Endereços para correspondência: Avenida Primo Alberto Bodanese, Centro, 89850-000, Quilombo, Santa Catarina, Brasil; zenacollet@gmail.com 